\title{
Conservation, matching, and the variable-interval schedule
}

\author{
JAMES ALLISON \\ Indiana University, Bloomington, Indiana 47405
}

\begin{abstract}
The conservation model was generalized to the variable-interval schedule by incorporating the concept of unscheduled instrumental responses, those which occur in the time before the next setup is due. Thirsty rats responded in constant-duration sessions on two 7-sec schedules that required one leverpress for 25 and 50 licks at a water tube and on a 14-sec 25-lick schedule. In accordance with the model, total licks decreased linearly as total presses increased, and the schedules facilitated leverpressing and suppressed licking relative to paired baseline levels of responding. While the matching model also gave a satisfactory fit to instrumental responding under the schedules, its two constants, representing asymptotic rate of responding and extraneous reinforcement, had anomalous values which led the model to predict that response rate would decrease as the rate of reinforcement increased, directly opposing its prediction for the constant-consumption experiments of its previous tests.
\end{abstract}

Theoretical analysis of performance under schedules commonly used in the operant conditioning laboratory is best begun with a clear understanding of constraints on performance that are purely experimental in character (Staddon, 1979). As a key example of such constraints, consider a hypothetical experiment in which the rat must run in a wheel for access to a retractable water tube. During each contingency session, 1,200 sec long, the schedule requires I sec of running for each access to water, and $C$ sec of drinking to free the wheel for the next bout of running. Figure 1 plots total time spent drinking against total time spent running, and defines the possible results in terms of a vector that represents the constraints imposed by the schedule. The slope of the upward vector is $\mathrm{C} / \mathrm{I}$, the nominal drink requirement divided by the nominal run requirement. Because the example schedule requires $\mathrm{I}=15 \mathrm{sec}$ of running and $\mathrm{C}=5 \mathrm{sec}$ of drinking, the slope, $\mathrm{C} / \mathrm{I}$, is .33 . If the rat fails to run, the data point representing performance under the schedule will be at the origin $(0,0)$. The more frequently the rat completes the scheduled sequence of response requirements, $\mathrm{I}+\mathrm{C}$, the further the point will move along the vector. Given no overrunning of either requirement and no fractional completion of $I+C$, the point will lie exactly on the vector. Otherwise, the point may lie slightly above or below the a priori vector with slope $\mathrm{C} / \mathrm{I}$.

The length of the vector reflects the maximum amount of responding that could occur. In the present example, the maximum amount of responding is constrained by the equation $\mathrm{N}(\mathrm{I}+\mathrm{C})=\mathrm{T}$, where $\mathrm{N}$ sig-

This research was supported in part by Grant MH $31970-01$ from NIMH. I thank Lawrence De Carlo and Richard Ellis for their help. Reprints may be obtained from James Allison, Department of Psychology, Indiana University, Bloomington, Indiana 47405 .

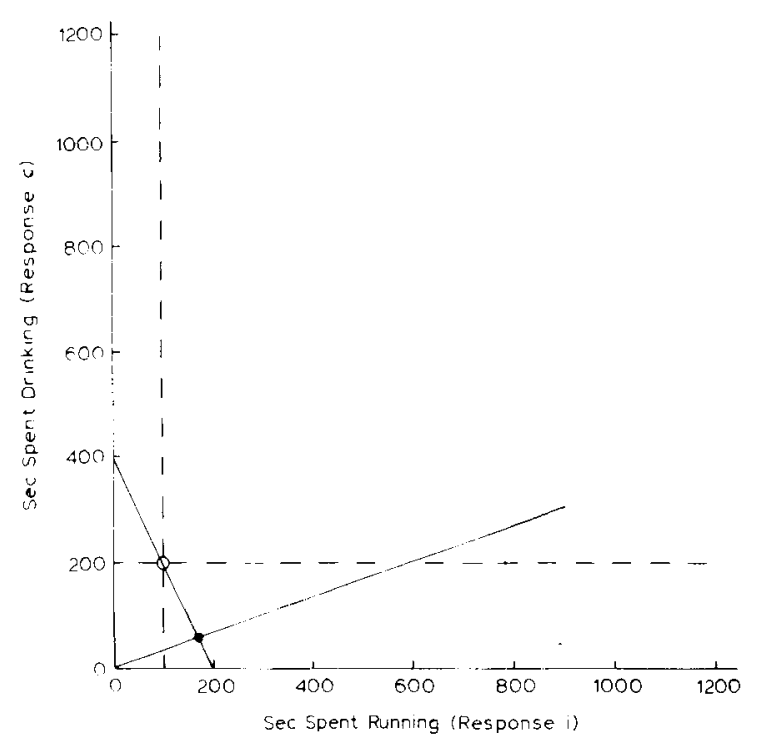

Figure 1. Hypothetical example of experimental and theoretical constraints. Time spent drinking (response c) as a function of time spent running (response $i$ ) in baseline (open circle) and on a schedule requiring 15 sec of running for 5 sec of drinking. Broken lines demarcate facilitation and suppression relative to baseline performance. The line with positive slope is the schedule vector. The line with negative slope is the line of theoretical constraint imposed by the conservation model, assuming that $k=2$.

nifies the number of times the rat completes the scheduled sequence of response requirements and $\mathrm{T}$ signifies the duration of the session. If the rat devoted the entire session to the two responses controlled by the schedule, the rat could complete the sequence no more than $\mathrm{N}=\mathrm{T} /(\mathrm{I}+\mathrm{C})$ times. The maximum amount of responding would then be NI sec of running, and NC sec of drinking, 900 and $300 \mathrm{sec}$ in the present example. The vector would be shortened by 
taking into account any inability to run and drink without pause.

Several theorists have proposed models for performance under schedules exemplified by Figure 1 (Allison, 1976; Allison, Miller, \& Wozny, 1979; Heth \& Warren, 1978; Mazur, 1975; Rachlin \& Burkhard, 1978; Staddon, 1979; Timberlake \& Allison, 1974). Each of these models attributes some importance to performance under a paired baseline condition in which the organism may perform each of the two responses without contraint by the schedule. In our example, the wheel would be unlocked and the tube freely available throughout the paired baseline session, also 1,200 sec long. The open circle in Figure 1 shows the (assumed) total time spent running and drinking in the paired baseline session. The broken lines through the base point divide the space into the four regions often used in classifying performance under the schedule. The upper right-hand quadrant denotes facilitation of both responses relative to basepoint performance. Suppression of both responses is denoted by the lower left-hand quadrant. The two remaining quadrants denote facilitation of one response and suppression of the other.

The present paper focuses on the conservation model (Allison, 1976; Allison et al. 1979; Shapiro \& Allison, 1978). This model assumes a tradeoff between the two responses controlled by the schedule, such that an increase in one response results in a linear decrease in the other response. In symbolic form, the model is approximated by the equation

$$
\mathrm{N}(\mathrm{kI}+\mathrm{C})=\mathrm{kO}_{\mathrm{i}}+\mathrm{O}_{\mathrm{c}}
$$

where I refers to the amount of response $\mathrm{i}$, and $\mathrm{C}$ to the amount of response $c$ specified by the schedule requirements. On the right-hand side, $\mathrm{O}_{\mathrm{i}}$ refers to the total amount of response $i$ under the paired baseline condition, $\mathrm{O}_{\mathrm{c}}$ to the amount of response $\mathrm{c}$. The $\mathrm{k}$ which appears on both sides is a dimensional constant, a positive number that specifies the number of measured response $c$ units equivalent to one measured unit of response $i$ in the theoretical tradeoff between the two responses. For example, if the underlying dimension happened to be energy, and one unit of response $i$ expended twice the amount expended by one unit of response $c, k$ would have a value of 2 (see Allison et al., 1979, for further details).

The predicted linear relation between the two responses can be derived by solving Equation 1 for the total amount of response $c$ performed under the schedule. The result is

$$
\mathrm{NC}=\left(\mathrm{kO}_{\mathrm{i}}+\mathrm{O}_{\mathrm{c}}\right)-\mathrm{k}(\mathrm{NI}),
$$

the equation for a line with intercept $\mathrm{kO}_{\mathrm{i}}+\mathrm{O}_{\mathrm{c}}$ and slope $-k$. Equation 2 predicts that response $c$ will decrease linearly as response i increases.
In Figure 1, the line with negative slope is the line of theoretical constraint imposed by Equation 2, assuming arbitrarily that $k=2$. The closed circle represents the model's prediction for performance under the schedule of our example. The model implies that the schedule of Figure 1 will facilitate response $i$ and suppress response $c$, and would make this same prediction for any schedule in which $\mathrm{C} / \mathrm{I}$ is less than $\mathrm{O}_{\mathrm{c}} / \mathrm{O}_{\mathrm{i}}$. Performance on any such schedule should lie at the point where the schedule vector intersects the line of theoretical constraint, and should therefore lie in the lower right-hand quadrant. It is also evident from Figure 1 that if $\mathrm{C} / \mathrm{I}$ is greater than $\mathrm{O}_{c} / \mathrm{O}_{i}$, the model predicts that the schedule will facilitate response $\mathrm{c}$, and suppress response $\mathrm{i}$ (reversibility).

Under the schedule of our example, one would not expect to see much "unscheduled" responding: running more than the I sec or drinking more than the $C$ sec prescribed by the nominal requirements of the schedule. Such unscheduled responding could be eliminated entirely if it were mechanically possible to brake the wheel instantly upon I sec of running, and retract the tube instantly upon $\mathrm{C}$ sec of drinking. In contrast is the conventional variable-interval schedule, which allows abundant opportunity for unscheduled responding in the form of instrumental responding in the time before the next setup is due. The model for such a schedule (Allison, Note 1) is

$$
\mathrm{N}(\mathrm{kI}+\mathrm{C})+\mathrm{kU}_{\mathrm{i}}=\mathrm{kO}_{\mathrm{i}}+\mathrm{O}_{\mathrm{c}},
$$

where $U_{i}$ signifies the total amount of response $i$ in the contingency session that would be classified as unscheduled responding. Solving Equation 3 for the total amount of response c performed under the variable-interval schedule,

$$
\mathrm{NC}=\left(\mathrm{kO}_{\mathrm{i}}+\mathrm{O}_{\mathrm{c}}\right)-\mathrm{k}\left(\mathrm{NI}+\mathrm{U}_{\mathrm{i}}\right) .
$$

Equation 4 predicts that response $\mathrm{c}$ will decrease linearly as response $i$ increases, whether response i be scheduled $(\mathrm{NI})$ or unscheduled $\left(\mathrm{U}_{\mathfrak{i}}\right)$.

Another notable feature of the variable-interval schedule is that the schedule requirements, I and C, place at best only an upper limit on the slope of the schedule vector. In actual practice, the slope at the end of the session will depend largely on the amount of unscheduled responding the organism happened to perform. Assuming that unscheduled occurrences of response $c$ are negligible, the slope at session end will be $\mathrm{NC} /\left(\mathrm{NI}+\mathrm{U}_{\mathrm{i}}\right)$, the total amount of response $\mathrm{c}$ divided by the total amount of response i. It follows that the slope will be $\mathrm{C} / \mathrm{I}$ only if $\mathrm{U}_{\mathrm{i}}=\mathrm{O}$. Otherwise, the slope can only be less than $\mathrm{C} / \mathrm{I}$.

The experiment reported here tested thirsty rats in 60-min sessions. During paired baseline sessions, a lever and a water tube were freely available throughout. During contingency sessions, the variable-interval 
schedule required one leverpress (I) for a fixed number of licks at the tube (C). Two 25-lick schedules used variable-interval schedules of 7 and $14 \mathrm{sec}$, and a third 7-sec VI schedule allowed 50 licks for each leverpress. These relatively short intervals were selected so as to provide nontrivial tests of the suppression of licking predicted by the model.

The major purpose of the experiment was to test the applicability of Equation 3. A secondary purpose was to examine how each response would be affected by varying the number of contingent licks and the interval. Earlier work on interval schedules suggests that the rate of instrumental responding might be increased by increasing $\mathrm{C}$ and decreasing the interval, but offers no certain guide to the outcome of the present experiment. The reason is that practically all published experiments on interval schedules used constant-consumption sessions rather than the constant-duration sessions used here. Typical examples are the well-known experiments by Catania and Reynolds (1968), who ended each session after a fixed number of reinforcements (e.g., after 61 4-sec accesses to grain). In consequence, the experiment also served as an unusual test of the matching model (Herrnstein, 1970), which generally gives a good account of the rate of instrumental responding on variable-interval schedules in constant-consumption sessions (de Villiers \& Herrnstein, 1976), but has seen little application to schedules tested in constant-duration sessions.

\section{METHOD}

\section{Subjects}

Six male 90-day-old albino rats, purchased from Laboratory Supply Co. (Indianapolis), served in the experiment.

\section{Apparatus}

The metal box, $60 \mathrm{~cm}$ long, $49 \mathrm{~cm}$ wide, and $18.5 \mathrm{~cm}$ high, had a sheet metal floor and a clear Plexiglas lid. One of the short walls was black plastic. Positioned on the plastic wall were a retractable lever and, to the right of the lever, a metal drinking tube with a $3-\mathrm{mm}$ aperture. Their centers were $8 \mathrm{~cm}$ apart, $8.5 \mathrm{~cm}$ above the floor, and equidistant from the nearest adjoining wall.

The tip of the tube, recessed $1 \mathrm{~cm}$ to prevent adventitious contacts, could be reached through a circular wall cutout, $1.5 \mathrm{~cm}$ wide. A motor-driven disk in the narrow space between the tip of the tube and the outer surface of the wall controlled access to the tube. The thin metal disk had a cutout in one 180-deg sector, opening and closing the access hole on alternate half-revolutions.

The motor-driven lever, $3.5 \mathrm{~cm}$ wide and $1.5 \mathrm{~cm}$ thick, projected into the box about $1.5 \mathrm{~cm}$ through a close-fitting retangular cutout. In its retracted position the end of the lever was flush with the inside surface of the wall. Applied to the end of the lever, a downward force of about $.28 \mathrm{~N}$ sufficed to close a miniature switch.

Illumination came from one red $1 . W$ light $3 \mathrm{~cm}$ above the lever and from another $3 \mathrm{~cm}$ above the tube. A noise generator near the box masked extraneous sounds.

In an adjoining room solid-state circuitry and film programmers controlled the two variable-interval schedules, 7 and $14 \mathrm{sec}$, constructed by the method of Catania and Reynolds (1968). A drinkometer unit (BRS/LVE) grounded to the floor of the box detected licks at the tube. Counters recorded total licks and total leverpresses for all six rats, and the number of times five of the six completed the lick requirement $(C)$.

\section{Procedure}

Each rat had an ample supply of laboratory chow pellets at all times, including the daily 60 -min test session. Eight days before the first session, daily watering in the home cage was confined to the 60 -min period reserved for the individual's test sessions. On the last 3 of these 8 days, immediately after the home-cage watering period, the rat had $15 \mathrm{~min}$ daily to explore the box in the absence of lever and tube. From the first test session to the last, the rats had no water outside the box.

Each rat went through four phases of testing in the order listed: baseline, two pretraining sessions on a simple fixed-ratio schedule, training on variable-interval schedules, and a second baseline phase. The pretraining schedule required 1 leverpress for each access to the tube and 25 licks for the next access to the lever. In pretraining, one rat needed two extra sessions for shaping. The lever appeared at the start of each training session; when the setup was due, 1 leverpress retracted the lever and opened the access hole; upon the last of the scheduled number of licks, the hole closed and the lever appeared again.

Five of the six rats had training on three schedules in the order listed: VI 7-sec, 1 press for 25 licks; VI 14-sec, 1 press for 25 licks; and VI 7-sec, 1 press for 50 licks. Rat R-1 had no training on the third schedule. Before the second baseline phase, three rats (R-4, $R-5$, and $R-6$ ) were retested on all three schedules in the reverse of the order listed above to check the recoverability of the key functional relations.

For each baseline phase and each schedule, testing continued until two variables met two stability criteria. The two variables were the total number of licks, and (in training only) the ratio total leverpresses/total licks. The stability criteria, applied to a block of four sessions in a row, were no monotone change across sessions, and a standard deviation no greater than $10 \%$ of the mean. As one further condition, the first baseline phase had at least eight sessions. The mean number of sessions was 8 in the first baseline phase, 8 on the first schedule, 7 on the second, 5 on the third, and 5 in the second baseline phase. Among the three rats retested, the mean number of sessions during retest was 7 on the first schedule, 5 on the second, and 16 on the third.

\section{RESULTS}

The analysis was based on the four sessions that met the stability criteria. Thus, eight sessions contributed to the overall baseline mean (four from the first phase, four from the second), and four or eight to the overall schedule mean (eight from the three rats tested twice on each.schedule). Neither response showed much variability over the criterion block of training sessions. Individual standard errors generally amounted to about $3 \%$ of the block mean number of licks, $7 \%$ of the block mean number of leverpresses.

Figure 2 plots total licks against total leverpresses for individuals and the group. The downward sloping lines, fitted by least-squares regression analyses, are the lines of theoretical constraint imposed by Equation 4 , the conservation model for the simple variableinterval schedule. The regression analyses treated the basepoint, $\left(\mathrm{O}_{\mathrm{i}}, \mathrm{O}_{\mathrm{c}}\right)$, the same as any schedule point, $\left(\mathrm{NI}+\mathrm{U}_{\mathrm{i}}, \mathrm{NC}\right)$, for reasons made evident by Equation $4, \mathrm{NC}=\left(\mathrm{kO}_{\mathrm{i}}+\mathrm{O}_{\mathrm{c}}\right)-\mathrm{k}\left(\mathrm{NI}+\mathrm{U}_{\mathrm{i}}\right)$. For a schedule vector passing through the basepoint, the equation implies that if the rat had performed the basepoint number of leverpresses $\left(\mathrm{NI}+\mathrm{U}_{\mathrm{i}}=\mathrm{O}_{i}\right)$, it should have performed the basepoint number of licks $\left(\mathrm{NC}=\mathrm{O}_{\mathrm{c}}\right)$.

Without exception, total licks decreased monotonically as total leverpresses increased, in accordance 


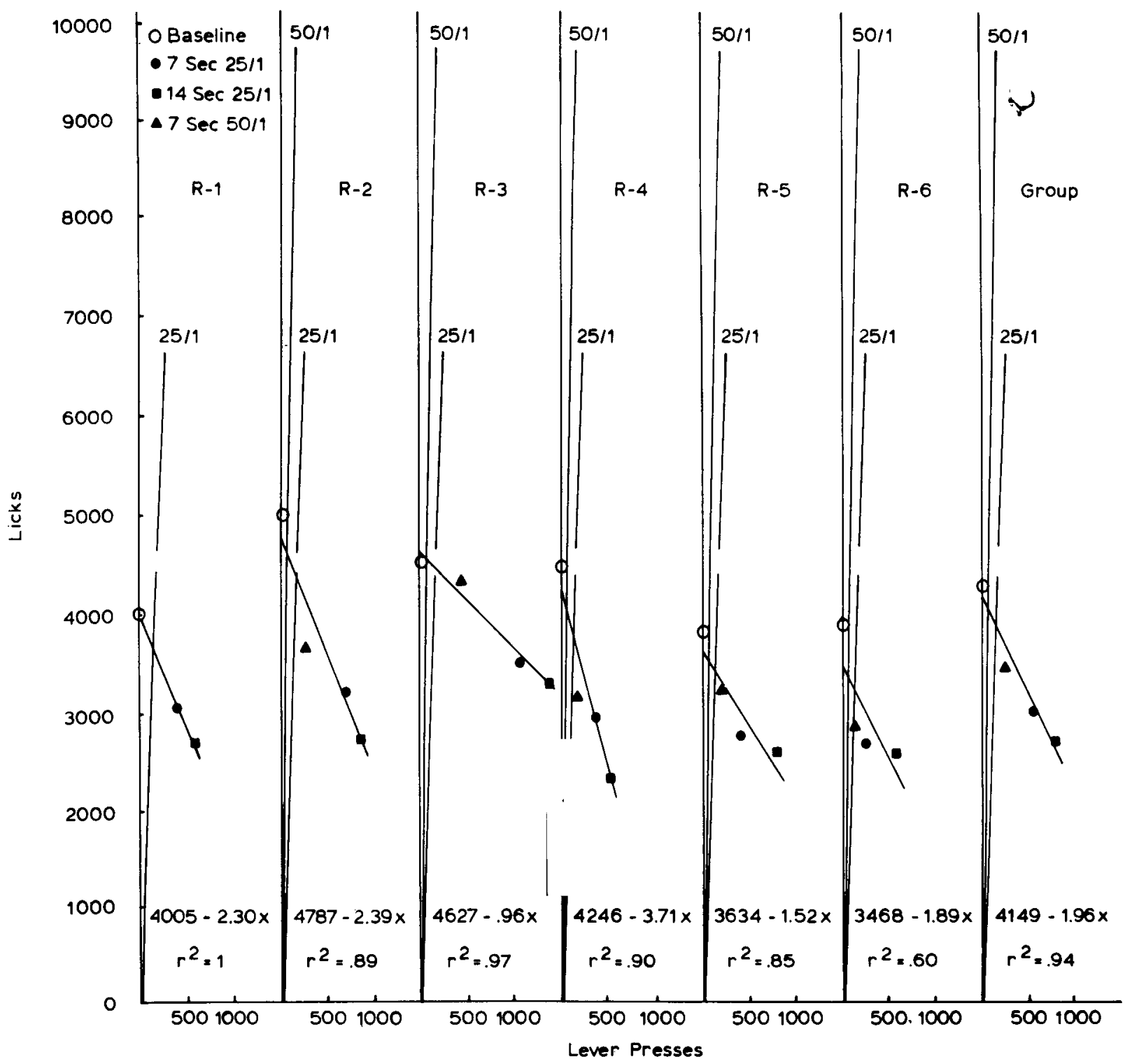

Figure 2. Total licks as a function of total leverpresses. The slope of upward vector, $25 / 1$ or $50 / 1$, is the upper limit on the slope of the vector the rat could have traced under the schedule. Each $50 / 1$ vector has one terminal point and each $25 / 1$ vector has two terminal points marking the maximum number of licks the rat could have performed under the schedule. The lower point is for the VI 14-sec, the upper for the VI 7-sec schedule.

with the model. Intercepts and slope constants appear near the bottom of Figure 2, along with coefficients of determination $\left(r^{2}\right)$. Except for R-6, the data points showed little scatter about the theoretical line of constraint. The coefficients of determination ranged from .60 to 1 among individual rats, and the linear model fit the group data well, $\mathrm{r}^{2}=.94$.

The fit was tested statistically by regressing the individuals' licks on the group mean number of leverpresses in the four conditions, baseline plus schedules. This regression plot was tested for linearity by comparing its correlation ratio, $\mathrm{e}^{2}=.71$, with its coefficient of determination, $\mathrm{r}^{2}=.67$. Because the difference was not significant $(\mathrm{p}>.25)$, there was no significant non- linear relation between leverpresses and licks. The linear product-moment correlation, $\mathrm{r}=-.82$, differed significantly from zero $(p<.001)$. To determine whether the model's error of prediction varied systematically across the four conditions, each individual's regression equation was used to predict the number of licks in each condition from the number of leverpresses observed. Linear regression analysis of the signed residuals, licks predicted minus licks observed, revealed no correlation between the residual and the number of leverpresses observed. The six values of $\mathrm{r}^{2}$ ranged from 0 to .0014 (mean $=0$ ), the intercept constants from -.67 to .099 (mean $=-.12$ ), the slope constants from -.0011 to .0044 (mean $=.0020)$. 
These analyses converge on the conclusion that the linear model fit the data well, and that the fit did not vary significantly among the four conditions.

Qualitative effects apparent in the grouped data on the right of Figure 2 can also be seen in each individual. Relative to baseline levels (open circles), the schedules (closed symbols) suppressed licking $[F(1,14)=104.20, p<.001]$ and facilitated leverpressing $[F(1,14)=45.46, p<.001]$. Both of these effects were predicted by the model. The basis of these predictions can be seen by examining the upward vectors in Figure 2. The slope shown at the top of each vector, $\mathrm{C} / \mathrm{I}$, is the upper limit on the slope of the vector the rat could have traced under the schedule in question. The rat could have traced that vector by performing no unscheduled leverpresses. Note that in every case the steepest possible schedule vector had a slope less than that of the basepoint vector, $\mathrm{O}_{\mathrm{c}} / \mathrm{O}_{\mathrm{i}}$ (total licks/total leverpresses in the paired baseline condition). The model therefore predicted the facilitation of leverpressing and the suppression of licking observed in the data. (For further explication of these two predictions, refer back to Figure 1.)

It must be pointed out that the suppression of licking by the 14-sec schedule was almost certainly trivial in three of six cases (R-2, R-3, and R-4): Probably none of these three could have attained the basepoint level of licking. The terminus of each vector, showing the upper limit on licking, was estimated by assuming $.5 \mathrm{sec}$ to perform the scheduled leverpress, $1 \mathrm{sec}$ to move from lever to tube, and a lick rate of 5 licks $/ \mathrm{sec}$. The lower terminus on each vector labeled $25 / 1$ is for the 14-sec schedule, and lies below the basepoints of $R-2, R-3$, and $R-4$. These estimates are probably conservative; more realistic estimates would probably lengthen each vector a little.

On the VI 7-sec schedule, changing the number of contingent licks from 25 to 50 increased total licks $[\mathrm{F}(1,14)=8.04, \mathrm{p}<.025]$ and decreased total leverpresses $[F(1,14)=9.52, p<.025]$. Similar effects have also been seen in rats pressing a lever for water on simple fixed-ratio schedules in 60 -min sessions [Allison et al., 1979). On the two 25-lick schedules, changing the interval from $14 \mathrm{sec}$ to $7 \mathrm{sec}$ also increased total licks $[\mathrm{F}(1,14)=4.84, \mathrm{p}<.05]$ and decreased total leverpresses $[F(1,14)=7.13, p<.025]$. In terms of the schedule vector, the net result of these two sets of effects was a systematic variation in the mean slope of the vector: 15.1 for the 7-sec 50-lick schedule, 6.7 for the 7-sec 25 -lick schedule, and 3.7 for the 14-sec 25 -lick schedule. The first of these three means was significantly greater than the second $[F(1,9)=101.45$, $\mathrm{p}<.001]$, and the second was greater than the third $[F(1,9)=12.90, p<.01]$.

None of the rats approached the steepest vector attainable on the schedule, because each performed many unscheduled leverpresses and a negligible number of unscheduled licks in the time needed to close the access hole (the latter averaged only two licks more than $C$ on each of the three schedules). Among the five rats whose total completions of the lick requirement were recorded (all but $\mathrm{R}-1$ ), total leverpresses could be sorted into two categories, scheduled and unscheduled. Relative to the number of scheduled responses, the 7-sec 50 -lick schedule produced the smallest number of unscheduled responses $(2.7 / 1)$, followed by the 7 -sec 25 -lick schedule (3.9/1) and the 14-sec 25 -lick schedule (7.1/1). The first of these three means was significantly less than the second $[F(1,8)=$ $5.91, p<.05]$, and the second was less than the third $[F(1,8)=40.38, p<.001]$. Statistical analysis of the total number of unscheduled leverpresses supported the same conclusions: The 7-sec 50-lick schedule encouraged the least amount of unscheduled responding ( 923 presses), followed by the 7 -sec 25 -lick schedule $(2,280)$ and the 14 -sec 25 -lick schedule $(3,646)$.

Figure 3 presents the results of the three rats tested twice on each schedule. With one minor exception, the functional relations revealed by the first test (Series 1) were the same as those of the second test (Series 2). The exception came on the first test of R-6, which licked slightly less on the 7-sec 50-lick schedule than on the 7-sec 25-lick schedule.

According to the matching model, the rate of instrumental responding, $R$, should vary systematically with the rate of reinforcement, r. The applicable equation (de Villiers \& Herrnstein, 1976, Equation 8), can be expressed as

$$
R=p r /(r+q),
$$

where $\mathrm{p}$ and $\mathrm{q}$ are constants determined empirically. Equation 5 was tested by calculating $\mathbf{R}$ (leverpresses per second, corrected for time spent licking) and tallying $r$ ( the number of licks per hour) for each of the

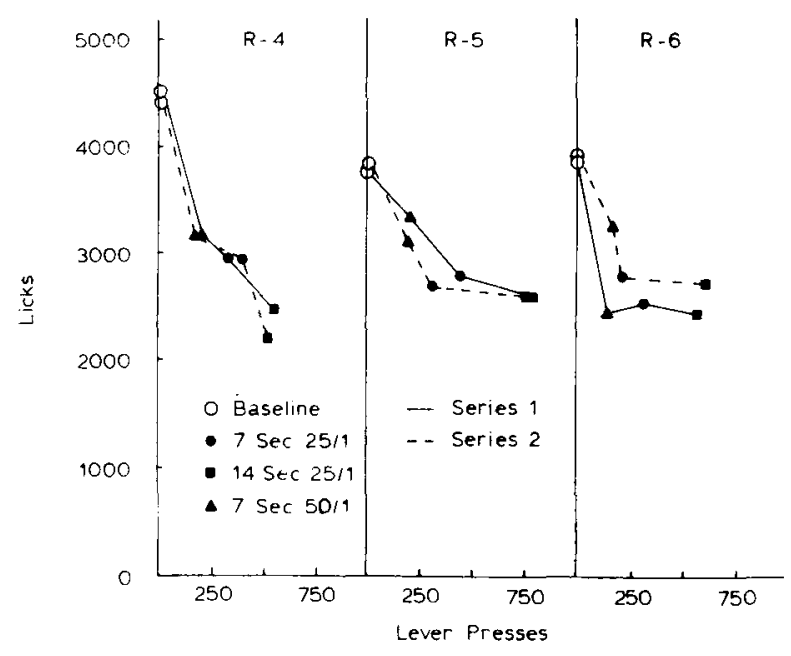

Figure 3. Total licks as a function of total leverpresses for the three rats tested twice on each schedule. 
three schedules. Least squares estimates of $p$ and $q$ were got by putting Equation 5 into linear regression form, $R=p-q(R / r)$, with intercept $p$ and slope $-q$. Based on the group means of $R$ and $R / r$ observed under the three schedules, the linear regression equation was $\mathrm{R}=.030+2432.071(\mathrm{R} / \mathrm{r}), \mathrm{r}^{2}=.996$. It follows that the least squares estimates were $p=.030$ and $\mathrm{q}=-2432.071$.

Because $\mathrm{p}$ supposedly refers to the asymptotic response rate, the small value of $p$, lower than any observed rate, is difficult to interpret in terms of the matching model. Because $q$ supposedly refers to the rate of extraneous reinforcement, reinforcement besides $r$, the negative value of $q$ is also problematical. But the preeminent question is how the rates observed compare with the rates predicted by Equation 5, setting $\mathrm{p}=.030$, and $\mathrm{q}=-2432.071$.

The comparison appears in Figure 4, which plots the corrected rate of leverpressing against the rate of reinforcement. Closed symbols show the rates observed, and the open symbols joined by continuous lines show the rates predicted by Equation 5 . The matching model ordered the rates correctly and accounted for a sizable proportion of the variance, $\mathrm{r}^{2}=.90$.

Note that the relation between the two rates directly opposes the relation predicted ordinarily. For the controlled-consumption experiments of its previous tests, the matching model predicted correctly that the rate of responding would increase with the rate of reinforcement, because in those experiments $p$ and $q$ were positive in sign. The theoretical effect of a negative $q$ can be seen most readily by rearranging Equation 5 with $q$ negative, $R=p /[1-(q / r)]$. With $q$ negative, as $r$ increases the subtrahend on the right grows smaller,

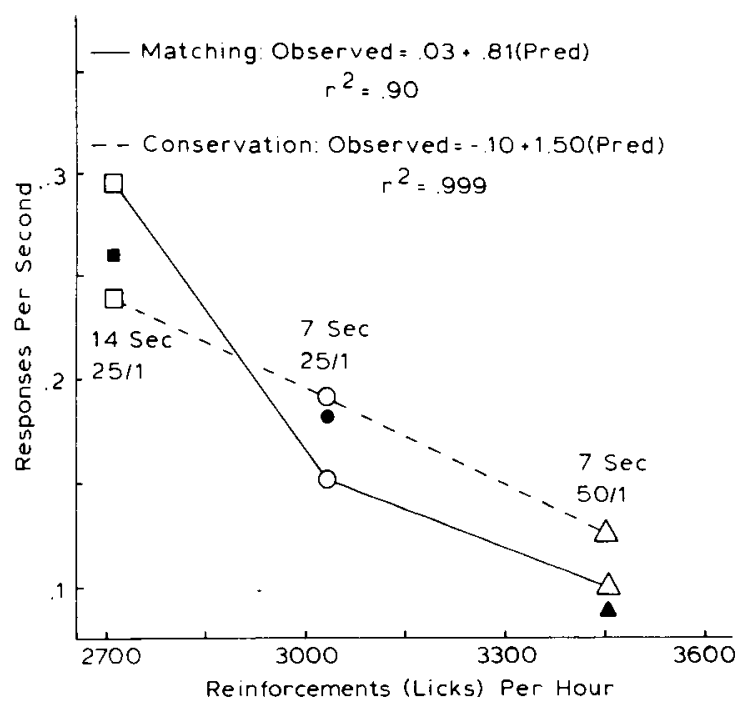

Figure 4. Rate of instrumental responding as a function of the rate of reinforcement, licks per hour. Closed symbols show values observed, open symbols values predicted by the matching model (continuous lines) and the conservation model (broken lines). so the denominator grows larger, the ratio smaller. If $\mathrm{q}$ is positive, $\mathrm{R}=\mathrm{p} /[1+(\mathrm{q} / \mathrm{r})]$, the ratio increases with $\mathrm{r}$, approaching $\mathrm{p}$ as a limit.

The open symbols joined by broken lines show the rates predicted by the conservation model, corrected for the predicted amount of time spent licking. The rates observed conformed closely to the rates predicted, $\mathbf{r}^{2}=.999$. Despite the apparent superiority of the conservation model, a comparison of the two models in terms of the squared differences between values predicted and observed showed no significant difference in their ability to fit the data $[t(2)=.19, \mathrm{p}>.80$ (two-tailed)].

The anomalous values of $p$ and $q$ stand in sharp contrast to the logically consistent estimates usually seen in tests of the matching model (de Villiers \& Herrnstein, 1976). The discrepancy suggests that the logic of the matching model, which applies so well to instrumental responding under the constantconsumption sessions of its earlier tests, may not apply to the constant-duration sessions of the present experiment. A few theorists have already recognized that the theoretical model for the constant-duration paradigm must sometimes differ in form from the corresponding model for the constant-consumption paradigm (Allison \& Timberlake, 1975; Allison, Note 3). Although Equation 5 fits the data well, the curious values responsible for the fit suggest that theorists concerned with the matching model might also do well to take account of the differences between the two paradigms.

Two of the empirical differences relate to the effects of the interval and the magnitude of reward upon rate of instrumental responding. In the controlledconsumption paradigm, rate generally increases with the magnitude of reward (de Villiers \& Herrnstein, 1976; Hall, 1966, p. 182); the opposite is true of the controlled-duration paradigm (Allison et al., 1979). The typical result appeared in the present experiment, where the mean corrected rates of leverpressing under the two 7 -sec schedules came to .182 presses/sec on the 25 -lick schedule, and only .088 on the 50 -lick schedule $[\mathrm{t}(4)=3.20, \mathrm{p}<.05$ (two-tailed)]. In the controlled-consumption paradigm, rate generally increases as the variable-interval decreases (Catania \& Reynolds, 1968). The opposite occurred under the two 25 -lick schedules, where the corrected rate on the 7 -sec schedule, .182, fell below the 14-sec rate of $.260[\mathrm{t}(5)=5.63, \mathrm{p}<.01$ (two-tailed) $]$.

Tests of the matching model ordinarily use the same magnitude of reward on all schedules, and thus define $r$ as the number of times the reinforcer was delivered per unit of time. The present analysis defined $r$ as the number of licks per hour, because the three schedules did not use the same magnitude of reward. Nevertheless, a subsequent analysis defined $r$ as the number of actual accesses to the water tube, regardless of the number of licks, in an effort to determine 
whether the resulting values of $p$ and $q$ would then conform to the logic of the matching model. The results of this analysis were even more anomalous than the original $\left(\mathrm{p}=-.054, \mathrm{q}=-133.350, \mathrm{r}^{2}=.86\right)$. The matching model ordered the two highest rates incorrectly, and accounted for only a modest proportion of the variance $\left(r^{2}=.17\right)$.

\section{DISCUSSION}

Besides the simple variable-interval schedule, conservation theory has given satisfactory accounts of performance under concurrent variable-interval schedules (Allison, Note 1), fixed-ratio schedules both simple (Allison et al. 1979; Allison, Note 2) and concurrent (Shapiro \& Allison, 1978; Allison, Note 1), simple cumulative-time schedules (Allison et al., 1979), and mixed schedules composed of two alternating cumulative-time components (Allison, 1976). The basic linear model has also had some success with an unusual variation of the simple fixed-ratio schedule. This variant required a fixed number of leverpresses for access to a food bin, but the rat was free to determine the size of the ensuing meal (Collier, Hirsch, \& Hamlin, 1972; Allison, Note 1). In addition to the wide variety of schedules, the successful applications cover a number of different species and responses, both instrumental and contingent.

Conservation theory assumes, and it has already been shown (Allison et al., 1979, Experiment 4), that the dimensional constant, $k$, may not be the same for two different pairs of responses. But, for any one pair, the theory presently assumes, for the sake of parsimony, that $\mathrm{k}$ does not depend on the kind of schedule in use, as long as the different schedules use the same units of measurement. An example would be two simple schedules, fixed ratio and variable interval, which both specify $I$ in terms of a required number of leverpresses and $\mathrm{C}$ in terms of a required number of licks at the water tube. Direct comparisons of different schedules are scarce, but the work reported here offers an opportunity for such a comparison. A previous experiment (Allison, Note 2) used the present apparatus to test 11 thirsty rats in $60-\mathrm{min}$ baseline and contingency sessions with simple fixedratio schedules. The three schedules required 1,4 , and 16 leverpresses for 50 licks at the water tube. Calculated across individuals, the mean value of $\mathrm{k}$ in that experiment was 1.50 , as compared with 2.13 in the present experiment. The difference was not significant $[\mathrm{t}(15)=1.09, \mathrm{p}>.20$ (two-tailed)]. Further comparisons of this sort, based on different schedules or different pairs of responses, may serve to clarify the fundamental character of the tradeoff between the responses controlled by the schedule.

History suggests that practically any model must eventually encounter some limits of applicability. Critics have already said, perhaps in truth, that the conservation model may not apply if the instrumental requirement is extremely large. The issue is still in doubt (Allison, 1979, Note 2). Perhaps the present results will dispel other reservations about the model's applicability to interval schedules.

Several of the alternative models mentioned in the introduction assume that performance under the constraints of the schedule represents a minimum deviation from basepoint performance free of schedule constraints (Heth \& Warren, 1978; Rachlin \& Burkhard, 1978; Staddon, 1979). This assumption implies that the rats in the present experiment should have held their unscheduled leverpressing to a minimum. This tactic would have put them on or near the steepest vector attainable on the schedule, the vector nearest the basepoint vector. Such models may have some difficulty in dealing with the fact that none of the rats approached very closely the steepest vector attainable. On the other hand, they might have approached it more closely with the help of an external signal accompanying the next setup (Segal, 1962).

Such models also imply that the rat faced with a concurrent fixed-ratio schedule will respond exclusively on the component whose vector is nearest the basepoint vector. Exclusive responding is often seen on such schedules, but there are recent reports of cases in which rats sampled both components extensively (Lea \& Roper, 1977; Shapiro \& Allison, 1978). As a result, they failed to approach the basepoint vector as closely as they might have (Allison, Note 3), and thus strayed further from the basepoint than these models would imply.

\section{REFERENCE NOTES}

1. Allison, J. Demand economics and conservation in ratio and interval schedules. Paper presented at the meeting of the Psychonomic Society, San Antonio, Texas, November 1978.

2. Allison, J. Consumption in an experimental welfare economy. Paper presented at the meeting of the Association for Behavior Analysis, Dearborn, Michigan, June 1979.

3. Allison, J. Constraints on performance in two elementary paradigms. Paper presented at the Second Harvard Symposium on Quantitative Analyses of Behavior, Cambridge, Massachusetts, June 1979.

\section{REFERENCES}

Allison, J. Contrast, induction, facilitation, suppression, and conservation. Journal of the Experimental Analysis of Behavior, 1976, 25, 185-198.

Allison, J. Remarks on Staddon's comment. Journal of Experimental Psychology: General, 1979, 108, 41-42.

Allison, J., Mille r, M., \& Wozny, M. Conservation in behavior. Journal of Experimental Psychology: General, 1979, 108, 4-34.

Allison, J., \& Timberlake, W. Response deprivation and instrumental performance in the controlled-amount paradigm. Learning and Motivation, 1975, 6, 122-142.

Catania, A. C., \& Reynolds, G. S. A quantitative analysis of the responding maintained by interval schedules of reinforcement. Journal of the Experimental Analysis of Behavior, 1968, 11, 327-383. 
Collier, G., Hirsch, E., \& Hamlin, P. The ecological determinants of reinforcement in the rat. Physiology \& Behavior, 1972, 9, 705-716.

De Villiers, P. A., \& Herrnstein, R. J. Toward a law of response strength. Psychological Bulletin, 1976, 83, 1131-1153.

HaLl, J. F. The psychology of learning. Philadelphia: Lippincott, 1966.

Hernnstein, R. J. On the law of effect. Journal of the Experimental Analysis of Behavior, 1970, 13, 243-266.

Heth, C. D., \& W ARren, A. G. Response deprivation and response satiation as determinants of instrumental performance: Some data and theory. Animal Learning \& Behavior, 1978, 6, 294-300.

LEA, S. E. G., \& Roper, T. J. Demand for food on fixed-ratio schedules as a function of the quality of concurrently available reinforcement. Journal of the Experimental Analysis of Behavior, 1977, 27, 371-380.

MAzUR, J. E. The matching law and quantifications related to Premack's principle. Journal of Experimental Psychology: Animal Behavior Processes, 1975, 1, 374-386.
Rachlin, H., \& Burkhard, B. The temporal triangle: Response substitution in instrumental conditioning. Psychological Review, 1978, 85, 22-47.

Segal, E. F. Exteroceptive control of fixed-interval responding. Journal of the Experimental Analysis of Behavior, 1962, 5, 49-57.

Shapiro, N., \& Allison, J. Conservation, choice, and the concurrent fixed-ratio schedule. Journal of the Experimental Analysis of Behavior, 1978, 29, 211-223.

Staddon, J. E. R. Operant behavior as adaptation to constraint. Journal of Experimental Psychology: General, 1979, 108, 48-67.

Timberlake, W., \& Allison, J. Response deprivation: An empirical approach to instrumental performance. Psychological Review, 1974, 81, 146-164.

(Received for publication May 10, 1979; revision accepted November 29, 1979.) 